\title{
PURWARUPA PENGENDALI KECEPATAN MOTOR INDUKSI 1 FASA VIA ANDROID
}

\author{
Abdullah Sani*, Ersi Eka Nur Jannah* \\ * Batam Polytechnics \\ Electrical Engineering study Program \\ Parkway Street, Batam Centre, Batam 29461, Indonesia \\ E-mail: sani@polibatam.ac.id.
}

\begin{abstract}
Abstrak
Motor adalah alat untuk mengubah energi listrik menjadi energi mekanik. Banyak peralatan listrik yang menggunakan motor terutama motor induksi 1 fasa. Untuk mendapatkan putaran kecepatan motor sesuai dengan kebutuhan maka diperlukan pengendalian kecepatan pada motor, untuk itu pada penelitian ini dilakukan penelitian dengan judul purwarupa pengendali kecepatan motor induksi 1 fasa via android. Pengendalian kecepatan dengan android membuat sistem ini lebih mudah diakses dan lebih praktis. Pengendalian kecepatan motor menggunakan modul Wemos Wi-Fi ESP8266 yang terhubung dengan driver motor (AC light dimmer), dengan mengatur Pulse Width Modulation (PWM) input pada driver maka motor akan berputar dengan kecepatan tertentu sesuai dengan PWM yang diberikan. Adapun pengujian yang telah dilakukan mengatur duty cycle PWM dengan kelipatan $10 \%$ dimulai dari $0 \%$ hingga 100\% didapatkan bahwa alat akan berputar ketika mencapai duty cycle PWM 30\%, tegangan keluaran dari alat adalah 60VAC hingga 220VAC, arus keluaran 0.35A hingga 0.65A, dan kecepatan putaran motor naik dari $1474 \mathrm{rpm}$ hingga 2625. Hal tersebut menunjukkan bahwa alat sudah bekerja dalam penelitian ini.
\end{abstract}

Kata kunci: 1 phase induction motor, android, Wi-Fi, AC light dimmer.

\begin{abstract}
The motor is a tool to convert electrical energy into mechanical energy. Much electrical equipment uses motors, especially 1 phase induction motors. To get the motor speed rotation following the needs, it is necessary to control the speed of the motor, for that in this study, the proposed research with the title prototype of 1 phase induction motor speed control via android. Speed control with Android makes this system more accessible and more practical. Motor speed control uses the Wemos Wi-Fi ESP8266 module which is connected to the motor driver (AC light dimmer), by adjusting the Pulse Width Modulation (PWM) input to the driver, the motor will rotate at a certain speed following the given PWM. The tests that have been carried out regulating the PWM duty cycle with a multiple of $10 \%$ starting from $0 \%$ to $100 \%$ found that the tool will rotate when reaching the PWM duty cycle $30 \%$, the output voltage of the tool is $60 \mathrm{VAC}$ to $220 \mathrm{VAC}$, the output current is $0.35 \mathrm{~A}$ to $0.65 \mathrm{~A}$, and the rotation speed of the motor rose from $1474 \mathrm{rpm}$ to $2625 \mathrm{rpm}$. This shows that the device was working in this study.
\end{abstract}

Keywords: 1 phase induction motor, android, Wi-Fi, AC light dimmer.

\section{PENDAHULUAN}

Motor adalah alat untuk mengubah energi listrik menjadi energi mekanik. Motor listrik banyak digunakan diberbagai alat rumah tangga maupun peralatan mesin di dunia industri. Kebanyakan alatalat rumah tangga dan alat industri yang kita temui pada umumnya menggunakan motor listrik AC (arus bolak balik). Motor AC dibagi menjadi 2 macam yakni motor induksi 1 fasa (peralatan rumah tangga) dan 3 fasa (peralatan industri) [1]. Motor induksi 1 fasa menggunakan tegangan 220VAC sedangkan motor induksi 3 fasa menggunakan tegangan 380VAC dan bentuk motor induksi 1 fasa lebih kecil daripada motor induksi 3 fasa.

Dalam pengaplikasian motor induksi 1 fasa kecepatan putar motor dapat diatur sesuai dengan yang kebutuhan [2]. Untuk mengubah kecepatan motor kita bisa mengubah nilai frekuensi, nilai tegangan input pada motor dan mengubah jumlah kutub motor [2]. Pada penelitian ini dengan mengatur tegangan terminal motor untuk mengontrol kecepatan motor dilakukan dengan cara mengatur duty cycle PWM 
pada input driver motor. Torsi motor pada motor induksi kapasitor permanen sebanding dengan kuadrat tegangan dijelaskan pada persamaan dibawah ini.

$$
T
$$

$$
=\frac{60\left[\left(I_{1}^{2}+a^{2} I_{2}^{2}\right)\left(R_{f}-R_{b}\right)+2_{a}\left(R_{f}+R_{b}\right) I_{1} I_{2} \sin \theta_{21}\right]}{2 \pi n_{s}}
$$

Dimana:

$$
\begin{gathered}
\widetilde{I}_{1}=\frac{\widetilde{V}_{1}\left(\hat{Z}_{22}-\hat{Z}_{12}\right)}{\widehat{Z Z}_{11} \widehat{Z Z}_{22}-\hat{Z}_{12} \hat{Z}_{21}} \\
\widetilde{I_{2}}=\frac{\widetilde{V}_{1}\left(\hat{Z}_{11}-\hat{Z}_{21}\right)}{\widehat{Z Z}_{11} \widehat{Z Z}_{22}-\hat{Z}_{12} \hat{Z}_{21}}
\end{gathered}
$$

maka dengan mengatur tegangan terminal motor akan menghasilkan kecepatan sinkron motor yang bervariasi.

Untuk mempermudah melakukan pengontrolan kecepatan pada motor dengan memanfaatkan kemajuan teknologi saat ini yaitu smartphone android. Android dapat dengan mudah digunakan untuk melakukan berbagai macam hal. Oleh karena itu penulis ingin meneliti rancang bangun pengendali kecepatan motor induksi 1 fasa menggunakan android agar bisa mengatur putaran motor hanya dengan menggunakan aplikasi yang telah didisain di android. Untuk komunikasi data penulis menggunakan wireless modul Wemos Wi-Fi ESP8266 yang memiliki jangkauan yang jauh [3].

\section{SISTEM YANG DIGUNAKAN}

Pada sistem ini terdiri dari perangkat keras (hardware) dan perangkat lunak (software). Setiap perangkat memiliki bagian masing-masing. Perangkat keras terdiri dari smartphone android, Wemos, driver motor dan motor AC. Perangkat lunak yaitu aplikasi yang didesain pada smartphone android [4-8]. Detail penjelasan dapat dilihat pada Gambar 1 dibawah ini.

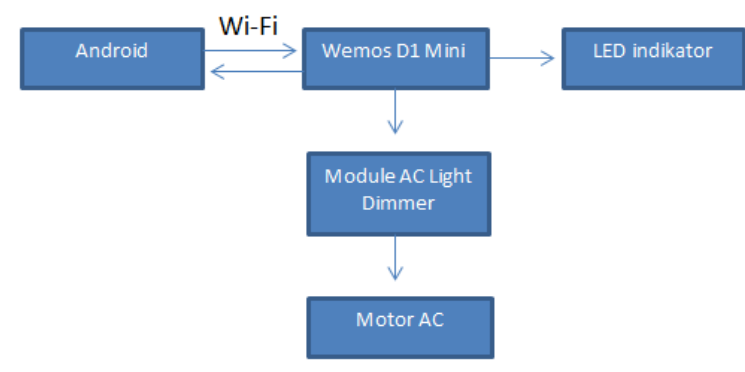

Gambar 1: Blok diagram sistem

Pada Gambar 1, Wemos D1 Mini merupakan mikrokontroler yang dapat tersambung dengan $\mathrm{Wi}-\mathrm{Fi}$, perangkat ini sebagai pengontrol modul AC Light dimmer yang terhubung dengan aplikasi pada perangkat smartphone. Modul AC light dimmer berfungsi untuk mengatur tegangan motor dengan memberikan input PWM. LED biru berfungsi sebagai indikator tersambung atau tidaknya sistem dengan $W_{i-}$ Fi smartphone.
Perancangan elektrikal merupakan wiring atau pengkabelan antara komponen-komponen yang digunakan. Pada Gambar 2 dibawah dapat dilihat bahwa adaptor dihubungkan ke regulator tegangan untuk membuat output tegangan menjadi $5 \mathrm{~V}$ DC. Rangkaian regulator tegangan dihubungkan ke pin ground dan vec pada Wemos D1 mini dan modul AC light dimmer. Pin zero crossing pada modul AC light dimmer dihubugkan ke pin D2 Wemos. Pin PWM modul AC light dimmer dihubungkan ke pin D1 pada Wemos. Untuk lebih jelasnya dapat dilihat pada gambar dibawah ini.

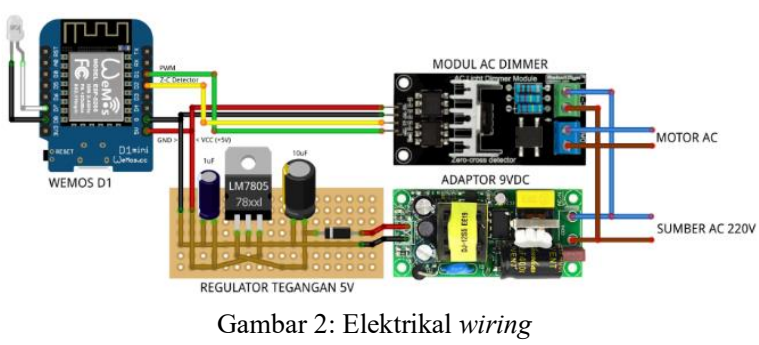

Pengemasan yang baik akan memberikan nilai tambah pada perangkat. Untuk itu pada penilitian ini selain perancangan perangkat keras dan lunak terdapat juga perancangan mekanik. Mekanik yang dibuat mengunakan box dan stop kontak yang dipadukan sehingga lebih kuat dan user-friendly. Detail desain yang digunakan dapat dilihat pada Gambar 3 dibawah ini.

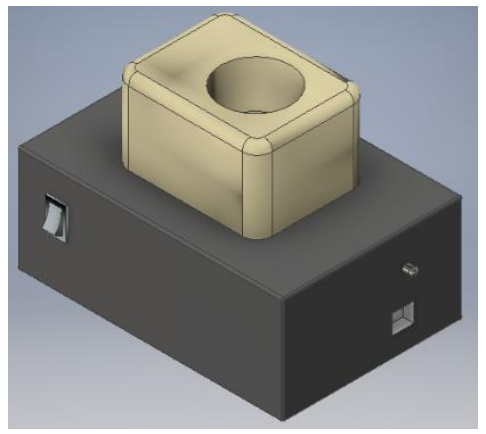

Gambar 3: Mekanik kotak

Pada Gambar 4 dibawah menjelaskan bagaimana sistem bekerja, dimulai dari terhubungnya perangkat sistem dengan android melalui media Wi-Fi. Ketika sistem sudah terhubung dengan Wi-Fi maka lampu indikator akan menyala, sedangkan ketika sistem belum terhubung dengan Wi-Fi maka lampu indikator akan berkedip terus. Setelah sistem terhubung, motor dalam keadaan diam. Untuk mengatur kecepatan motor terlebih dahulu harus menghidupkan tombol speed control yang ada di smartphone. Tombol ini berfungsi sebagai pengaman, lalu geser slide bar control untuk mengubah kecepatan motor. Pergeseran slide bar merepresentasikan persentase duty cycle PWM. Data yang didapat dari slide bar diproses oleh Wemos dan dikirim ke motor melalui AC light dimmer dan motor akan berputar. Untuk mematikan sistem, matikan tombol speed control lalu keluar dari aplikasi yang ada di smartphone. 


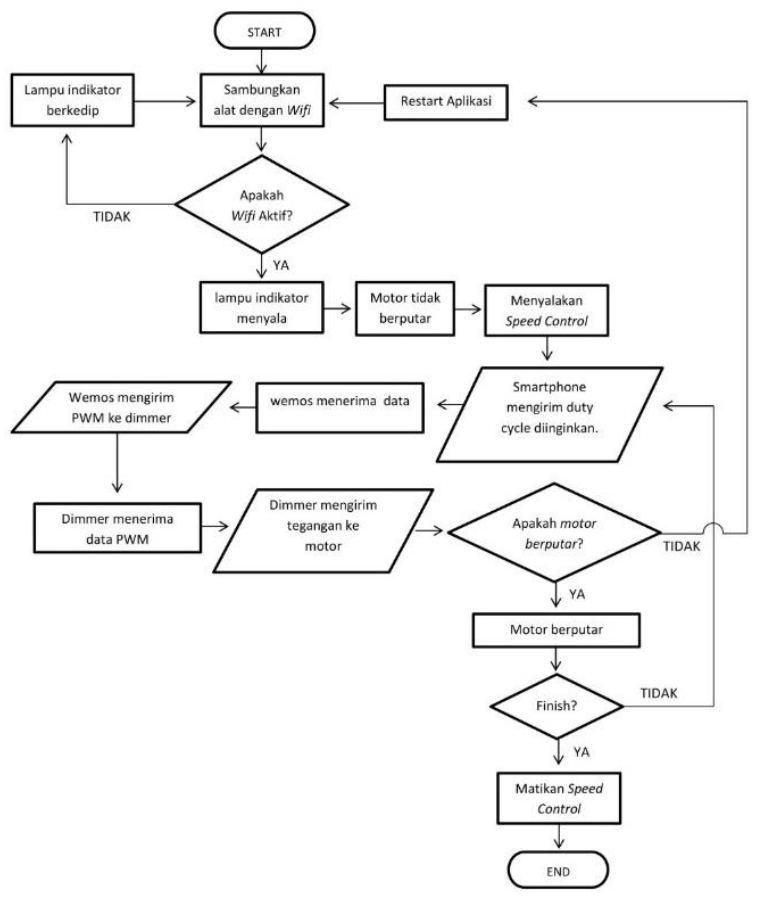

Gambar 4: Diagram alir system pengendali kecepatan motor

\section{HASIL DAN PEMBAHASAN}

Aplikasi android yang digunakan pada penelitian ini adalah app inventor. Tampilan aplikasi untuk sistem ini dapat dilihat pada Gambar 5 dibawah ini. Tampilan terdiri dari koneksi yang terbaca oleh smartphone (Server), tombol on/off dari speed control dan slide bar untuk mengatur kecepatan motor. Detail gambar dari aplikasi yang telah didesain dapat dilihat dibawah ini.

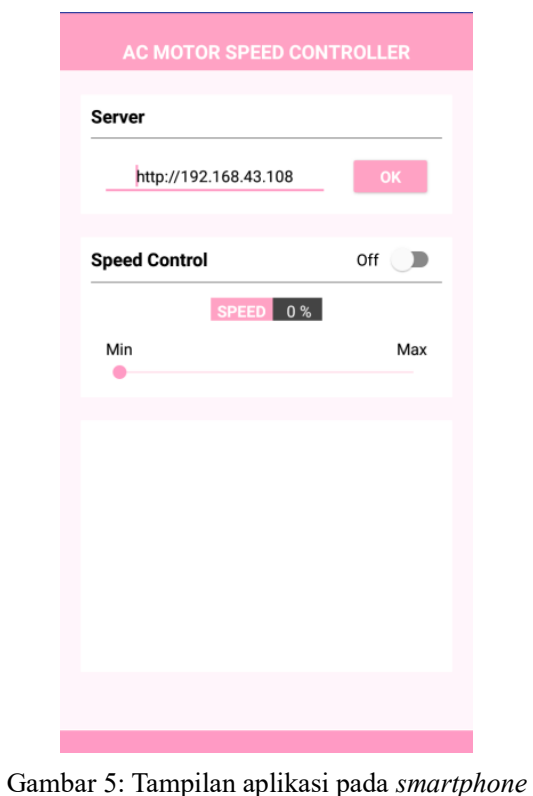

Data yang dikirimkan oleh smartphone adalah data yang diperoleh dari pergeseran slide bar (min-max), data ini berupa nilai presentase untuk nilai PWM. Nilai ini yang digunakan untuk mengatur kecepatan motor.
Ada tiga pengujian yang dilakukan pada penelitian ini. Pertama pegujian aplikasi, pengujian aplikasi dilakukan untuk mengetahui keberfungsian dari aplikasi yang dibuat, sudah berjalan dengan baik atau belum. Tabel 1 menunjukan hasil pengujian keberfungsian aplikasi. Kedua pengujian konektifitas antara aplikasi dengan perangkat keras. Pengujian konektifitas dilakukan untuk mengetahui jarak yang masih memungkinkan terbaca oleh smartphone terhadap perangkat keras. Tabel 2 menunjukan hasil pengujian konektifitas.

Tabel 1. Hasil pengujian aplikasi android

\begin{tabular}{|l|l|l|l|}
\hline No & Tombol & Fungsi & Status \\
\hline 1 & OK & $\begin{array}{l}\text { Untuk meng- } \\
\text { koneksikan antara } \\
\text { aplikasi dengan } \\
\text { perangkat keras }\end{array}$ & Berhasil \\
\hline 2 & Off/On & $\begin{array}{l}\text { Untuk mengaktifkan } \\
\text { slide bar speed control }\end{array}$ & Berhasil \\
\hline 3 & Slide bar & $\begin{array}{l}\text { Untuk mengatur } \\
\text { kecepatan motor }\end{array}$ & Berhasil \\
\hline
\end{tabular}

Tabel 1 diatas menunjukan bahwa aplikasi telah berfungsi dengan baik

Tabel 2. Hasil pengujian konektifitas

\begin{tabular}{|l|l|}
\hline $\begin{array}{l}\text { Jarak } \\
\text { (Meter) }\end{array}$ & Status \\
\hline 5 & Berhasil \\
\hline 10 & Berhasil \\
\hline 15 & Berhasil \\
\hline 20 & Berhasil \\
\hline 25 & Berhasil \\
\hline 30 & Berhasil \\
\hline 35 & Berhasil \\
\hline 40 & Berhasil \\
\hline 45 & Berhasil \\
\hline 50 & Tidak Berhasil \\
\hline 55 & Tidak Berhasil \\
\hline
\end{tabular}

Tabel 2 diatas menunjukan bahwa smartphone/aplikasi android berhasil terhubung dengan baik pada jarak $<45 \mathrm{~m}$

Pengujian yang ketiga, pengujian perangkat keras. Pengujian ini dilakukan dengan tujuan untuk mengetahui keberfungsian dari Wemos dan driver motor/ AC light dimmer. Pengujian dilakukan dengan membuat sinyal PWM pada Wemos dengan duty cycle tertentu dan kemudian dihubungkan ke input AC light dimmer. Gambar 6 merupakan PWM dengan duty cycle 30\%. Perubahan duty cycle akan menyebabkan perubahan tegangan pada keluaran AC light dimmer sehingga membuat kecepatan putaran motor menjadi 
berubah-ubah. Tabel 3 menunjukan hasil dari pengujian perangkat keras dengan duty cycle yang berbeda-beda.

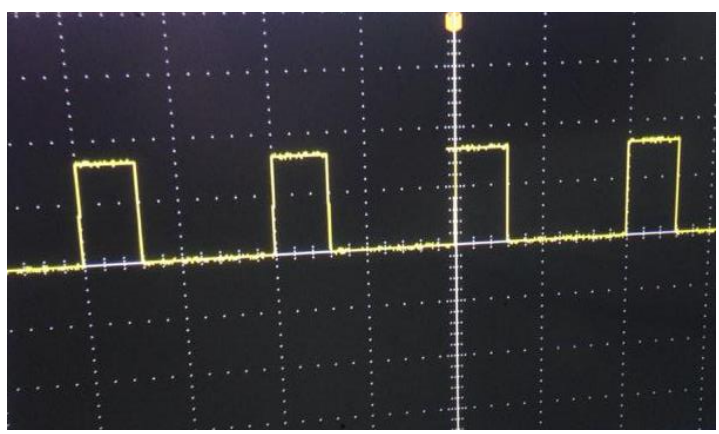

Gambar 6: PWM dengan 30\% duty cycle

Tabel 3. Hasil pengujian perangkat keras

\begin{tabular}{|l|l|l|}
\hline $\begin{array}{l}\text { Duty cycle } \\
(\%)\end{array}$ & $\begin{array}{l}\text { Tegangan } \\
\text { (VAC) }\end{array}$ & rpm \\
\hline 30 & 60,00 & 1474 \\
\hline 40 & 87,3 & 1872 \\
\hline 50 & 117,3 & 2045 \\
\hline 60 & 144,7 & 2306 \\
\hline 70 & 169,3 & 2463 \\
\hline 80 & 190,4 & 2547 \\
\hline 90 & 207,4 & 2569 \\
\hline 95 & 214 & 2600 \\
\hline 100 & 220 & 2625 \\
\hline
\end{tabular}

Tabel 3 diatas menunjukan bahwa perangkat keras berfungsi dengan baik.

Data pada Tabel 3, menjelaskan bahwa semakin besar nilai duty cycle PWM yang diberikan,maka semakin besar tegangan keluaran pada AC light dimmer, sehingga kecepatan putaran motor juga semakin cepat begitu juga untuk sebaliknya semakin pelan putaran motor maka semakin kecil tegangannya

\section{KESIMPULAN}

Berdasarkan data dari pengujian, penelitian pengendali kecepatan motor induksi 1 fasa via android sudah berhasil dan berfungsi dengan baik. Ini dapat dilihat pada kecepatan motor yang dapat diatur melalui aplikasi android. Motor dapat berputar dengan kecepatan, 1000rpm $<$ kecepatan $<2600$ rpm dengan duty cycle, $30 \%<$ duty cycle $<100 \%$. Jarak koneksi antara smartphone dengan perangkat keras maksimum 45 meter.

\section{REFERENSI}

[1] Dwi Hadidjaja, Onny Setyawati dan Didik Rahadi Santoso," Jurnal EECCIS" Analisis Pengaturan Putaran Motor Satu Fasa dengan Parameter Frekuensi Menggunakan Power Simulator
(PSIM), vol. 9. pp. 1, Des.2015.

[2] Agus Sutriyono,"Rancang Bangun Pengendali Motor 1 Fasa Dengan Metode zero Crossing Detector berbasis Arduino" Proyek Akhir, Universitas Muhammadiyah Surakarta, Surakarta, 2017.

[3] Novi Dharmayani, "Sistem Pendeteksi Alarm Kendaraan Bermotor Berbasis Internet Of Things" Proyek Akhir, Politeknik Negeri Batam, Batam,2018.

[4] Rahadi, D. R. (2014). Pengukuran Usability Sistem Menggunakan Use Questionnaire Pada Aplikasi Android. Jurnal Sistem Informasi , 6, 661-671.

[5] Septryanti, A., \& Fitriyanti. (2017). Rancang Bangun Aplikasi Kunci Pintu Otomatis Berbasis Mikrokontroler Arduino Menggunakan Smartphone Android. Journal of Computer Engineering System and Science, 2, 59-63

[6] Silvia, A. F., Haritman, E., \& Muladi, Y. (2014). Rancang Bangun Akses Kontrol Pintu Gerbang Berbasis Arduino dan Android. Electrans, 13, 110

[7] Wang, R., Enck, W., Reeves, D., Zhang, X., Ning, P., Xu, D., et al. (2015). EASEAndroid: Automatic Policy Analysis and Refinement for Security Enhanced Android via Large-Scale Semi-Supervised Learning. The 24th USENIX Security Symposium. Washington: USENIX Association.

[8] Muhammad Arifin, Egi Fazar Firrizqi, Abdullah Sani, (2019) Akses Kontrol Kotak Kunci Ruang Kelas Berbasis Smartphone Android. Jurnal Integrasi, vol. 1, 63-67. 